\title{
Evolution of Morphology of Nano-Scale CuO Grown on Copper Metal Sheets in 5 wt\% NaCl Solution of Spray Fog Environment
}

\author{
Hao-Long Chen, Tsung-Hsun Chiang, Ming-Cheng Wu \\ Department of Electronic Engineering, Kao Yuan University, Kaohsiung City, Chinese Taipei. \\ Email: hlchern@ms18.hinet.net
}

Received July $1^{\text {st }}, 2012$; revised August $8^{\text {th }}, 2012$; accepted August $18^{\text {th }}, 2012$

\begin{abstract}
Nano-scale copper oxide with various morphologies is synthesized via the thermal oxide method and growth in a $5 \mathrm{wt} \%$ $\mathrm{NaCl}$ solution of spray fog environment. The nano-scale copper oxide is grown on copper metal sheets via the thermal oxide method at $650^{\circ} \mathrm{C}$ for 60 minutes. Nano-scale copper oxide grains and nanowires are induced on copper metal sheets then placed in $5 \mathrm{wt} \% \mathrm{NaCl}$ solution of salt spray fog environment. Significant changes in particle size and morphology are observed with increasing salt spray fog treatement time. The morphology of nano-scale copper oxide varies from nanograins to nanowires, Ctahedron, and icositetrahedron. The morphologies and structures of the obtained nano-scale copper oxide are investigated by scanning electron microscopy and energy-dispersive spectroscopy. Possible growth mechanisms are discussed.
\end{abstract}

Keywords: Nano; CuO; Morphology; $\mathrm{NaCl}$ Solution; Spray Fog

\section{Introduction}

Nanoscale one-dimensional (1D) and two-dimensional (2D) materials such as nanowires, nanorods, nanoribbons, and nanosheets have attracted a lot of interest due to their unique physical properties and potential applications in nanodevices.

Copper oxide $(\mathrm{CuO})$ is a well known p-type semiconductor and a photovoltaic material. It has a narrow band gap $(1.2 \mathrm{eV}) . \mathrm{CuO}$ is desirable due to its availability and abundance of the starting materials, non-toxicity, and low production cost [1]. Consequently, it is widely used in applications such as catalysis [2], sensors [3], solar cells $[4,5]$, and field-emission emitter materials [6]. However, the chemical and physical properties of $\mathrm{CuO}$ strictly depend on its size and morphology [7]. Many studies have synthesized various $\mathrm{CuO}$ nanostructures. A number of methods have been used to synthesize and control the size and morphology of nano-scale $\mathrm{CuO}$, such as thermal evaporation [1], solution synthesis [7], thermal oxidation [8], sol-gel [9], hydrothermal method [10], electrospinning [11] and microwave hydrothermal synthesis [12].

These methods have been used to synthesize $\mathrm{CuO}$ nanomaterials with various morphologies, such as nanoparticles, 1D nanowires, nanorods, and nanobelts; 2D nanosheets, nanoleaves, and nanowiskers; and three-dimensional peachstone-like, boat-like, and ellipsoid-like na- nostructures [10]. The morphology of nano-scale $\mathrm{CuO}$ is related to growth environment conditions, in addition to processing methods.

In this work, nano-scale $\mathrm{CuO}$ with various morphologies is synthesized via the thermal oxide method and growth in a $5 \mathrm{wt} \% \mathrm{NaCl}$ solution of spray fog environment. The morphology of nano-scale $\mathrm{CuO}$ varied from nanograins to nanosheets and nanoneedles with increaseing salt spray fog treatement time. Possible growth mechanisms are discussed.

\section{Experimental Procedure}

$\mathrm{CuO}$ with various morphologies was synthesized via the thermal oxide method and growth in a $5 \mathrm{wt} \% \mathrm{NaCl}$ solution of spray fog environment.

Copper $(99.99 \mathrm{wt} \% \mathrm{Cu})$ substrate samples with dimensions of $10 \mathrm{~mm}$ (width) $\times 10 \mathrm{~mm}$ (length) $\times 1 \mathrm{~mm}$ (thickness) were prepared according to the following procedure: the substrate was polished with various grinding papers $(400,600,800,1200,2000$, and 4000 grade) and then ultrasonically cleaned with acetone, ethanol, and de-ionized water for 10 minutes sequentially to remove the impurities and native oxides on its surface. The samples were then dried by blowing with high-pressure nitrogen gas.

Thermal oxidation of the $\mathrm{Cu}$ sheets was carried out in 
a resistance-heated tube furnace in a pure oxygen atmosphere at a temperature of $650^{\circ} \mathrm{C}$ for 60 minutes. Nano-scale $\mathrm{CuO}$ grains were induced on the copper metal sheets and then placed in $5 \mathrm{wt} \% \mathrm{NaCl}$ solution of spray fog environment. The treatment times of the samples in the spray fog environment were 1, 7, 14, 21, and 28 days, respectively. The temperature of the spray fog environment was kept in $45^{\circ} \mathrm{C}$.

The surface morphology of the samples was observed using a scanning electron microscope (SEM, Hitachi $\mathrm{S} 3000 \mathrm{~N}$, Japan) operated at $30 \mathrm{kV}$. The chemical composition of the nanomaterials was confirmed by energydispersive X-ray analysis (EDX, Horiba, Japan). The phases and structure of the nanomaterials were identified by grazing-incidence X-ray diffraction (GIXRD) using a Rigaku D/MAX 2500 multipurpose X-ray thin-film diffractometer with monochromatic high-intensity $\mathrm{CuK} \alpha$ radiation $(\lambda=0.15418 \mathrm{~nm})$.

\section{Results and Discussion}

\subsection{Phase and Structure Analysis}

The X-ray diffraction patterns of polycrystalline $\mathrm{Cu}$ metal sheets prepared by polishing and thermal oxidation are shown in Figure 1. Figure 1(a) shows the diffraction peaks of an as-polished $\mathrm{Cu}$ metal sheet, which are assigned to the (111), (200) and (220), planes of face-centered cubic (fcc) $\mathrm{Cu}$. This result is in agreement with the standard data from JCPDS card No. 85-1326. The XRD patterns of CuO samples on $\mathrm{Cu}$ metal sheets prepared via thermal oxidation are shown in Figure 1(b). The XRD peaks can be indexed as monoclinic structured $\mathrm{CuO}$ (JCPDS card No. 80-1917), cubic structured cuprous oxide $\left(\mathrm{Cu}_{2} \mathrm{O}\right)$ (JCPDS card No. 78-2076), and fcc $\mathrm{Cu}$ metal from the substrate (JCPDS card No. 85-1326). The diffraction peaks of the monoclinic structured $\mathrm{CuO}$ are assigned to the (110), $(-111)$, (111), (20-2), (11-3), (31-3), (400), and (22-3) planes. The peaks of cubic structured $\mathrm{Cu}_{2} \mathrm{O}$ are assigned to the (111) and (200) planes.

Figure 2 shows the XRD patterns of nano-scale $\mathrm{CuO}$ prepared via the thermal oxide method and then placed in a $5 \mathrm{wt} \% \mathrm{NaCl}$ solution of spray fog environment for 0 (only thermal oxidation), 1 , and 28 days, respectively. The diffraction pattern of the copper(II) chloride $\left(\mathrm{CuCl}_{2}\right)$ appeared for the sample prepared via thermal oxidation and then placed in a $5 \mathrm{wt} \% \mathrm{NaCl}$ solution of spray fog environment for 1 day, in addition to the original production peaks of $\mathrm{CuO}, \mathrm{Cu}_{2} \mathrm{O}$, and $\mathrm{Cu}$ metal substrate (Figure 2(b)). The diffraction peak of the monoclinic structured $\mathrm{CuCl}_{2}$ is assigned to the (-405) planes (JCPDS card No. 79-1635). The peaks of $\mathrm{CuCl}_{2}$ increased with increasing salt spray fog treatment time. Figure 2(c) shows that the diffraction planes of $\mathrm{CuCl}_{2}$ were (002), (111), (112), $(-313)$, and $(-221)$ for the sample treated using $5 \mathrm{wt} \%$

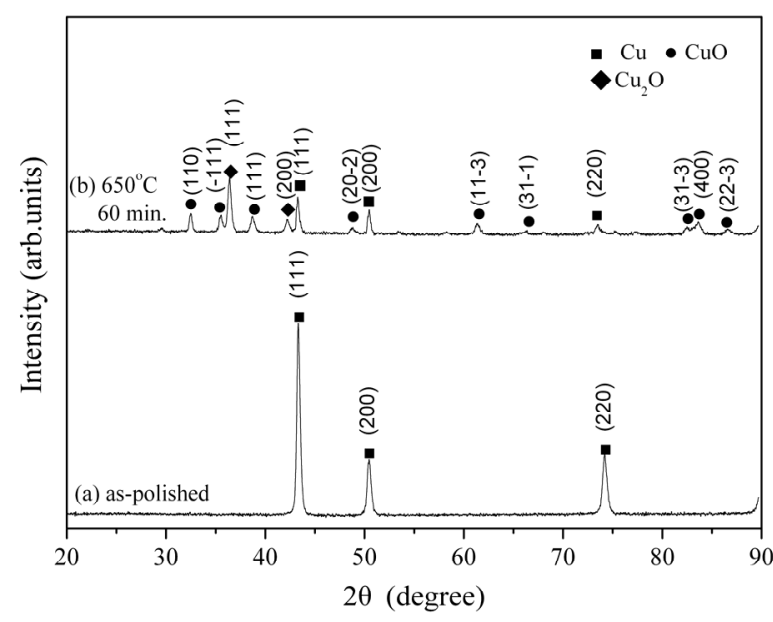

Figure 1. XRD patterns of polycrystalline $\mathrm{Cu}$ metal sheets prepared by (a) polishing and (b) thermal oxidation.

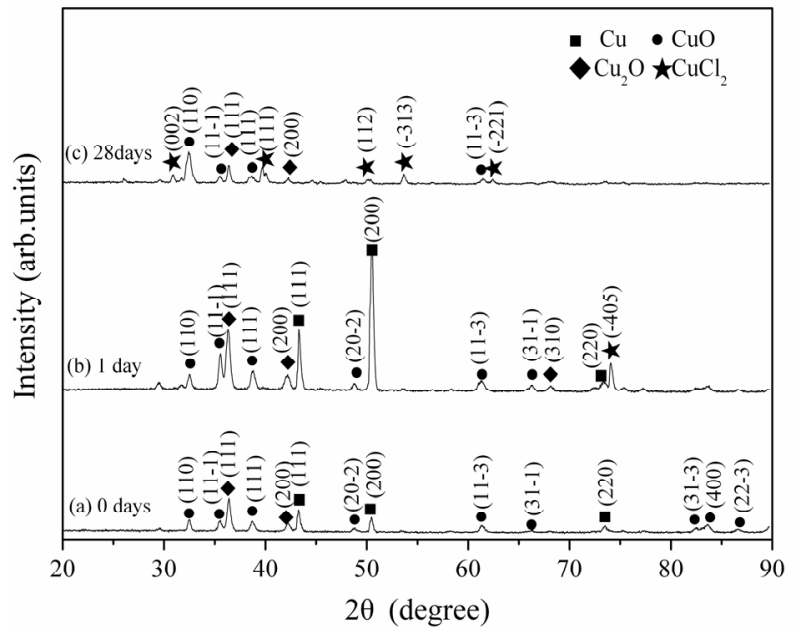

Figure 2. XRD patterns of nano-scale copper oxide prepared by thermal oxide method followed by exposure to 5 wt \% NaCl solution of spray fog environment for (a) 0 (only thermal oxidation); (b) 1; and (c) 28 days.

$\mathrm{NaCl}$ solution of spray fog for 28 days.

The XRD results indicate that the main phases of the nano-scale $\mathrm{CuO}$ grown on pure $\mathrm{Cu}$ metal substrates after thermal oxidation were $\mathrm{CuO}$ and $\mathrm{Cu}_{2} \mathrm{O} . \mathrm{CuCl}_{2}$ was induced on pure $\mathrm{Cu}$ metal substrates when the samples were placed in $5 \mathrm{wt} \% \mathrm{NaCl}$ solution of spray fog environment.

\subsection{Morphology Observation}

Figure 3 shows the surface morphology of polycrystalline $\mathrm{Cu}$ metal sheets prepared by polishing. The surface of the $\mathrm{Cu}$ metal sheets did not have any surface chemical products.

SEM micrographs of nano-scale $\mathrm{CuO}$ and nanowires 


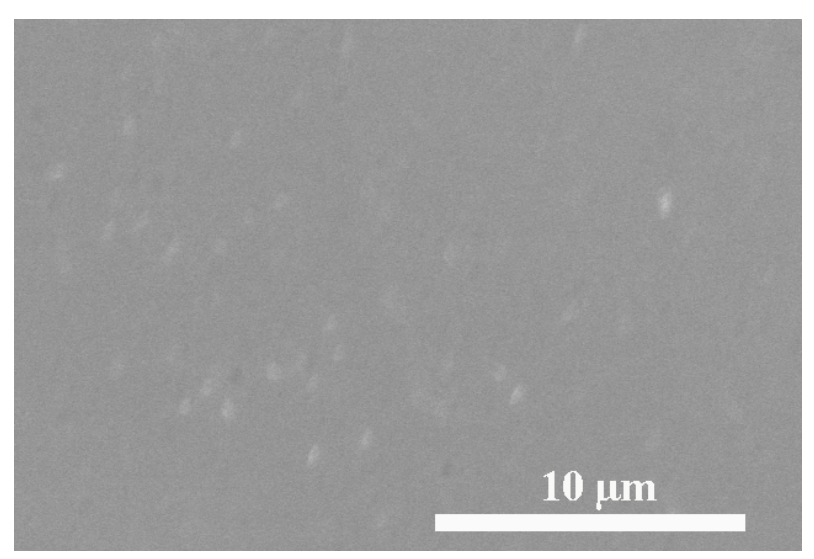

Figure 3. Surface morphology of polycrystalline Cu metal sheet prepared by polishing.

grown via thermal oxidation on $\mathrm{Cu}$ metal sheets for 60 minutes at $650^{\circ} \mathrm{C}$ are shown in Figure 4(a). The morphologies of nano-scale surface products formed after thermal oxidation followed by exposure to $5 \mathrm{wt} \% \mathrm{NaCl}$ solution of spray fog environment for various durations significantly change, as shown in Figures 4(b)-(f). Figure 4(a) shows Ctahedral-shaped grains about $1 \mu \mathrm{m}$ aggregated on the nanowire after 1 day in a $5 \mathrm{wt} \% \mathrm{NaCl}$ solution of spray fog environment. The Ctahedral-shaped grain size increased with increasing spray fog treatment time. The Ctahedral-shaped grains are replaced by a sixhorn-shaped icositetrahedron. Each crystal has six apexes, each of which is connected to four sides to form an icositetrahedron [13]. Icositetrahedron-shaped crystals can be observed in the Figure 4(d). When the salt spray fog treatment time was increased to 28 days, the edges and corners of the icositetrahedron-shaped crystals become more extrusive (Figure 4(f)). The crystal size increased from about $1 \mu \mathrm{m}$ ( 1 day) to about $8 \mu \mathrm{m}$ (14 days) and then decreased to about $4 \mu \mathrm{m}$ ( 28 days).

The chemical composition of the nano-scale oxide grown on pure $\mathrm{Cu}$ metal substrates after thermal oxidation and salt spray fog treatment was confirmed by EDX. Figure 5 shows the nanowire crystal after thermal oxidation that is $\mathrm{CuO}$. The nano-scale oxide grown in a salt spray fog environment, which formed Ctahedral-shaped and icositetrahedron-shaped crystals, was $\mathrm{Cu}_{2} \mathrm{O}$. The crystal shape similar to a tetrahedron was $\mathrm{CuCl}_{2}$, as shown in Figure 6.

\subsection{Growth Mechanisms of Nano-Scale Copper Oxides}

There are two major growth models, namely vapor-liquid-solid (VLS) catalyst-assisted growth [8] and vaporsolid (VS) growth [14], for describing the growth of 1D nanostructures. Kaur et al. [8] synthesized $\mathrm{CuO}$ nanowires via the thermal oxidation of copper foils and found that the growth of the nanowires is initiated by the condensation of the vapor of the material at the tip of the droplet in the VLS process. The morphology of a 1D structure has a round droplet, which is usually found near the tip of the wire. However, the $\mathrm{CuO}$ nanowires prepared via thermal oxidation had no droplets at their tips, indicating that the VLS mechanism is not applicable.

The oxidation process of the $\mathrm{Cu}$ metal substrate includes two steps [15]:

$$
\begin{aligned}
& 4 \mathrm{Cu}+\mathrm{O}_{2} \rightarrow 2 \mathrm{Cu}_{2} \mathrm{O} \\
& 2 \mathrm{Cu}_{2} \mathrm{O}+\mathrm{O}_{2} \rightarrow 4 \mathrm{CuO}
\end{aligned}
$$

In this work, the nano-scale $\mathrm{Cu}$ grains and nanowires were induced on copper metal sheets by thermal oxidation. The $\mathrm{Cu}$ atoms or ions diffused to the surface and then reacted with oxygen ions that formed $\mathrm{CuO}$ in the initial stage. When thickness of $\mathrm{CuO}$ film increased with increasing oxidation time, $\mathrm{Cu}$ atoms or ions difficult diffusion to reactive with surface $\mathrm{O}_{2}$. Consequently, the $\mathrm{CuO}, \mathrm{Cu}_{2} \mathrm{O}$, and $\mathrm{Cu}$ phases were obtained in the samples.

The following mechanism has been proposed for the oxidation and reduction processes of copper in $\mathrm{NaCl}$ solution [16]:

$$
\begin{aligned}
& \mathrm{Cu}+\mathrm{Cl}^{-} \rightarrow \mathrm{CuCl}_{(\mathrm{ads})}+\mathrm{e} \\
& \mathrm{CuCl}_{(\mathrm{ads})} \rightarrow \mathrm{CuCl}_{(\mathrm{film})} \\
& \mathrm{CuCl}+\mathrm{e} \rightarrow \mathrm{Cu}+\mathrm{Cl}^{-} \\
& \mathrm{CuCl}_{(\mathrm{ads})}+\mathrm{Cl}^{-} \rightarrow \mathrm{CuCl}_{2} \\
& \mathrm{CuCl}_{2}^{-} \rightarrow \mathrm{Cu}^{2+}+2 \mathrm{Cl}^{-}+\mathrm{e}
\end{aligned}
$$

The reactions in Equations (3)-(5) represent the dissolving, chelating, and film-forming processes of copper, respectively. The reactions in Equations (6) and (7) are a competition of the growth and dissolution of the corrosion products on the surface of the specimens.

Nano-scale $\mathrm{CuO}$ and $\mathrm{Cu}_{2} \mathrm{O}$ were grown on the $\mathrm{Cu}$ metal substrate and then placed in $5 \mathrm{wt} \% \mathrm{NaCl}$ solution of spray fog environment. The morphologies of nano-scale $\mathrm{CuO}$ variation were dominated by an electrochemical mechanism. Zhao et al. [13] synthesized $\mathrm{Cu}_{2} \mathrm{O}$ microcrystals with various shapes using an electrochemical method and found that the $\mathrm{Cu}_{2} \mathrm{O}$ crystal shapes changed from Ctahedral to icositetrahedral with increasing solution $\mathrm{PH}$ value. The cations in the solution have little influence on the morphology of copper, but the anions have a complex influence. Hu et al. [17] found that $\mathrm{Cl}^{-}$ can form in certain local regions of copper. Ctahedron, nanowire, and prism structures are obtained besides cubic copper when the concentration of $\mathrm{Cl}^{-}$reaches a certain value. The $\mathrm{Cl}^{-}$adsorption on special crystal faces may 

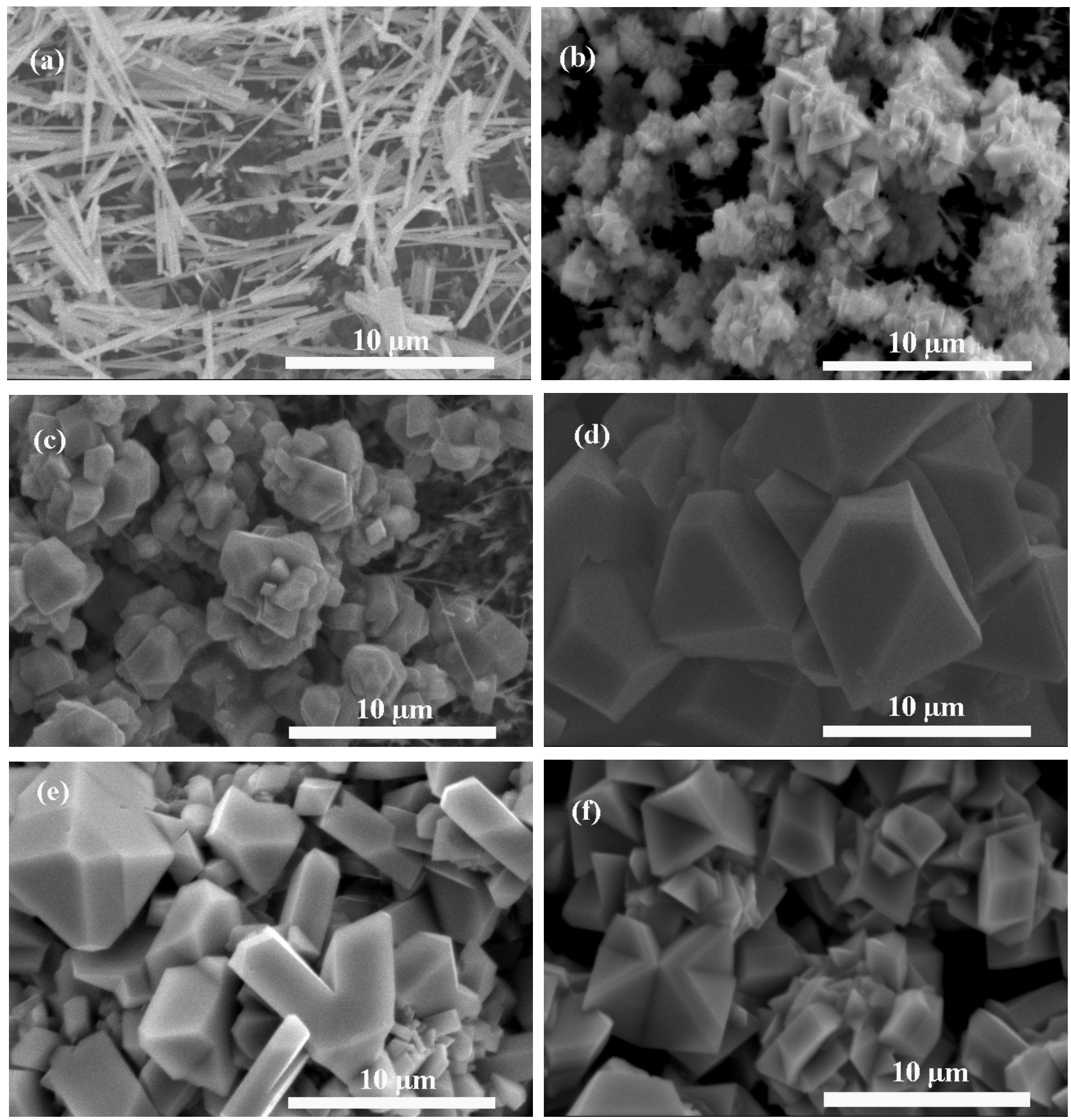

Figure 4. Surface morphology of polycrystalline $\mathrm{Cu}$ metal sheet prepared by thermal oxide method followed by exposure to 5 wt \% NaCl solution of spray fog environment for (a) 0 (only thermal oxidation); (b) 1; (c) 7; (d) 14; (e) 21; and (f) 28 days.

cause some crystal faces with a faster growth rate to gradually shrink or even disappear with the growth of crystals. This reasonably explains why the crystal size increased from about $1 \mu \mathrm{m}$ (1 day) to about $8 \mu \mathrm{m}$ (14 days) and then decreased to about $5 \mu \mathrm{m}$ ( 28 days). The diffraction plane $(-405)$ of $\mathrm{CuCl}_{2}$ disappeared when the samples were treated using $5 \mathrm{wt} \% \mathrm{NaCl}$ solution of spray fog for 28 days.

\section{Conclusions}

Nano-scale $\mathrm{CuO}$ grains and nanowires were induced on copper metal sheets and then placed in $5 \mathrm{wt} \% \mathrm{NaCl}$ solution of spray fog environment. The following conclusions were obtained:

- Nano-scale copper oxide likely developed as $\mathrm{CuO}$ nanograins and $\mathrm{CuO}$ nanowires, and then Ctahedral-shaped $\mathrm{Cu}_{2} \mathrm{O}$ and tetrahedral-shaped $\mathrm{CuCl}_{2}$ ag- 

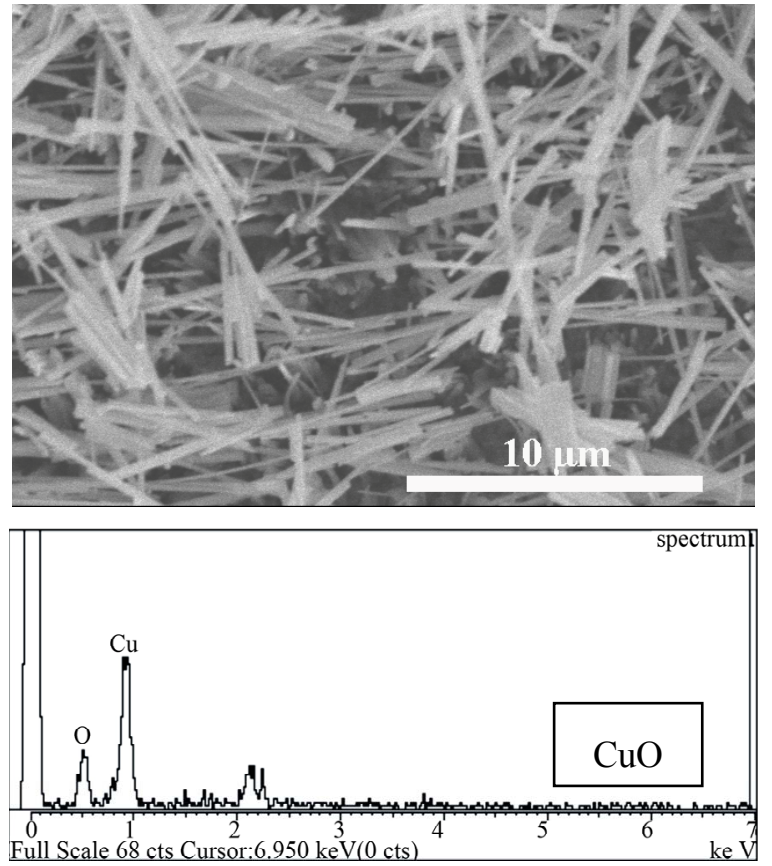

Figure 5. SEM images and EDX spectrum of $\mathrm{CuO}$ nanowires.
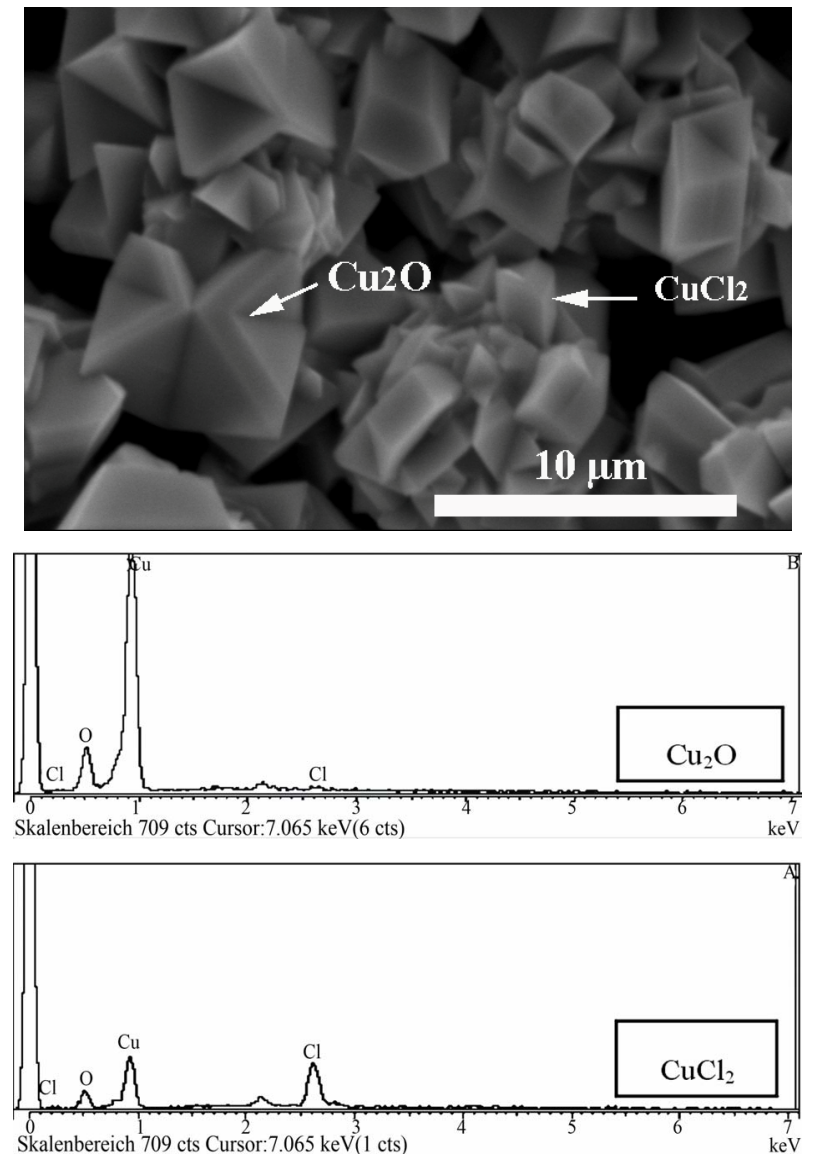

Figure 6. SEM images and EDX spectrum of $\mathrm{Cu}_{2} \mathrm{O}$ icositetrahedron and $\mathrm{CuCl}_{2}$ tetrahedron. gregated on the nanowires. When the salt spray fog treatment time was increased, the Ctahedral-shaped $\mathrm{Cu}_{2} \mathrm{O}$ and tetrahedral-shaped $\mathrm{CuCl}_{2}$ mixed to form icositetrahedron-shaped $\mathrm{Cu}_{2} \mathrm{O}$ crystals.

- $\mathrm{CuO}$ nanowires prepared via thermal oxidation regarding likely follow the VS mechanism.

- Nano-scale $\mathrm{CuO}$ and $\mathrm{Cu}_{2} \mathrm{O}$ were grown on a $\mathrm{Cu}$ metal substrate and then placed in $5 \mathrm{wt} \% \mathrm{NaCl}$ solution of spray fog environment. The morphology of nanoscale copper oxide was dominated by an electrochemical mechanism.

- The $\mathrm{Cl}^{-}$adsorption on special crystal faces may cause some crystal faces with a faster growth rate to gradually shrink or even disappear with the growth of crystals.

\section{Acknowledgements}

The authors are grateful to the Ministry of Economic Affairs (MOEA) Science and Technology Development Program, Taiwan, Republic of China for supporting of this research under grant 99-EC-17-A-05-S1-122.

\section{REFERENCES}

[1] M. F. Al-Kuhaili, "Characterization of Copper Oxide Thin Films Deposited by the Thermal Evaporation of Cuprous Oxide $\left(\mathrm{Cu}_{2} \mathrm{O}\right)$," Vacuum, Vol. 82, No. 6, 2008, pp. 623629. doi:10.1016/j.vacuum.2007.10.004

[2] S. Ohya, S. Kaneco, H. Katsumata, T. Suzuki and K. Ohta, "Electrochemical Reduction of $\mathrm{CO}_{2}$ in Methanol with Aid of $\mathrm{CuO}$ and $\mathrm{Cu}_{2} \mathrm{O}$," Catalysis Today, Vol. 148, No. 3-4, 2009, pp. 329-334. doi:10.1016/j.cattod.2009.07.077

[3] F. Teng, W. Q. Yao, Y. F. Zheng, Y. T. Ma, Y. Teng, T. G. Xu, S. H. Liang and Y. F. Zhu, "Synthesis of FlowerLike CuO Nanostructures as a Sensitive Sensor for Catalysis," Sensor and Actuators B: Chemical, Vol. 134, No. 2, 2008, pp. 761-768. doi:10.1016/j.snb.2008.06.023

[4] S. Anandan, X. G. Wen and S. H. Yang, "Room Temperature Growth of $\mathrm{CuO}$ Nanorod Arrays on Copper and Their Application as a Cathode in Dye-Sensitized Solar Cells," Materials Chemistry and Physics, Vol. 93, No. 1, 2005. pp. 35-40. doi:10.1016/j.matchemphys.2005.02.002

[5] R. P. Wijesundera, "Fabrication of the $\mathrm{CuO} / \mathrm{Cu}_{2} \mathrm{O}$ Heterojunction Using an Electrodeposition Technique for Solar Cell Applications," Semiconductor Science and Technology, Vol. 25, No. 4, 2010, Article ID: 045015. doi:10.1088/0268-1242/25/4/045015

[6] Y. W. Zhu, T. Yu, F. C. Cheong, X. J. Xu, C. T. Lim, V. B. C. Tan, J. T. L. Thong and C. H. Sow, "Large-Scale Synthesis and Field Emission Properties of Vertically Oriented CuO Nanowire Films," Nanotechnology, Vol. 16, No. 1, 2005, pp. 88-92. doi:10.1088/0957-4484/16/1/018

[7] F. Bayansal, S. Kahraman, G. Cankaya, H. A. Cetinkara, H. S. Güder and H. M. Cakmak, "Growth of Homogenous 
CuO Nano-Structured Thin Films by a Simple Solution Method," Journal of Alloys and Compounds, Vol. 509, No. 5, 2011, pp. 2094-2098.

doi:10.1016/i.jallcom.2010.10.146

[8] M. Kaur, K. P. Muthe, S. K. Despande, S. Choudhury, J. B. Singh, N. Verma, S. K. Gupta and J. V. Yakhmi, "Growth and Branching of $\mathrm{CuO}$ Nanowires by Thermal Oxidation of Copper," Journal of Crystal Growth, Vol. 289, No. 2, 2006, pp. 670-675. doi:10.1016/j.jcrysgro.2005.11.111

[9] G. N. Rao, Y. D. Yao and J. W. Chen, "Evolution of Size, Morphology, and Magnetic Properties of CuO Nanoparticles by Thermal Annealing," Journal of Applied Physics, Vol. 105, No. 9, 2009, Article ID: 093901.

[10] Z. P. Cheng, J. M. Xu, H. Zhong, X. Z. Chu and J. Song, "Hydrogen Peroxide-Assisted Hydrothermal Synthesis of Hierarchical CuO Flower-Like Nanostructures," Materials Letters, Vol. 65, No. 13, 2011, pp. 2047-2050. doi:10.1016/j.matlet.2011.04.021

[11] S. W. Choi, J. Y. Park and S. S. Kim, "Growth Behavior and Sensing Properties of Nanograins in CuO Nanofibers," Chemical Engineering Journal, Vol. 172, No. 1, 2011, pp. 550-556. doi:10.1016/j.cej.2011.05.100

[12] A. P. Moura, L. S. Cavalcante, J. C. Sczancoski, D. G. Stroppa, E. C. Paris and A. J. Ramirez, "Structure and Growth Mechanism of $\mathrm{CuO}$ Plates Obtained by Microwave-Hydrothermal without Surfactants," Advanced Pow- der Technology, Vol. 21, No. 2, 2010, pp. 197-202. doi:10.1016/j.apt.2009.11.007

[13] W. Y. Zhao, W. Y. Fu, H. B. Yang, C. J. Tian, R. X. Ge, C. J. Wang, Z. L. Liu, Y. Y. Zhang, M. H. Li and Y. X. $\mathrm{Li}$, "Shape-Controlled Synthesis of $\mathrm{Cu}_{2} \mathrm{O}$ Microcrystals by Electrochemical Method," Applied Surface Science, Vol. 256, No. 7, 2010, pp. 2269-2275. doi:10.1016/j.apsusc.2009.10.051

[14] R. S. Wanger and W. C. Ellis, "Vapor-Liquid-Solid Mechanism of Single Crystal Growth," Applied Physics Letters, Vol. 4, No. 5, 1964, pp. 89-90. doi:10.1063/1.1753975

[15] C. H. Xu, C. H. Woo and S. Q. Shi, "Formation of $\mathrm{CuO}$ Nanowires on $\mathrm{Cu}$ Foil," Chemical Physics Letters, Vol. 399, No. 1-3, 2004, pp. 62-66. doi:10.1016/j.cplett.2004.10.005

[16] B. Guo, P. Zhang, Y. P. Jin and S. K. Cheng, "Effects of Alternating Magnetic Field on the Corrosion Rate and Corrosion Products of Copper," Rare Metals, Vol. 27, No. 3, 2008, pp. 324-328. doi:10.1016/S1001-0521(08)60138-2

[17] M. Y. Hu, K. G. Zhou, C. G. Wang and R. Xu, "Cl- Induced Synthesis of Submicron Cubic Copper Particles in Solution," Journal of University of Science and Technology Beijing, Mineral, Metallurgy, Material, Vol. 15, No. 5, 2008, pp. 659-664. doi:10.1016/S1005-8850(08)60123-1 